\title{
Qual é o liberalismo da Lei Chapelier? Seu significado para os contemporâneos e para a historiografia francesa dos séculos XIX e XX
}

João Tristan Vargas

Resumo: Este artigo propõe-se discutir o significado que teve a Lei Chapelier, de 1791, na França, na época em que foi aprovada, do ponto de vista dos representantes do poder público, dos trabalhadores e dos patrões. Propõe-se também questionar o significado que Ihe foi atribuído pela historiografia francesa dos séculos XIX e XX e pela brasileira da atualidade.

Palavras-chave: liberalismo; relações de trabalho; Lei Chapelier

Abstract: This article approaches the 1791 Chapelier Law meaning on France, in it's time, from public power representatives', workers' and entrepreneurs' point of view. Approaches too the meaning XIX/XX centuries French and actual Brazilian historiography attaches to it.

Keywords: liberalism; work relations; Chapelier Law

Tanto na historiografia nacional como na internacional, dois textos são vistos como marcos para o estatuto do trabalhador na época contemporânea: a Lei Chapelier, de 1791 (a designação alude ao nome de seu autor, deputado à Assembleia Constituinte francesa reunida de 1789 àquele ano), que proibia as associações de classe, e o tratado de Versalhes, de 1919, que recomendava aos países signatários a adoção de medidas que melhorassem a condição do trabalhador. O primeiro seria o introdutor, no âmbito das relações entre patrões e trabalhadores, do conceito de "liberdade de trabalho", que seria contraditório com a ideia de regulamentação do trabalho e que representaria o nexo fundamental do liberalismo naquelas relações. O segundo teria significado a ruptura com aquele conceito, facilitando a criação de leis sociais em que estas ainda não existissem. Uma vertente historiográfica bastante consolidada sugere que o apego a tal conceito, por parte dos detentores de poder decisório durante a Primeira República no Brasil, teria constituído um sério óbice às iniciativas de criação de tais leis naquele período ${ }^{1}$ : regulamentar o trabalho

* Doutor em História Social pela Unicamp. Professor da UFOPA - Univ. Fed. do Oeste do Pará. jgaram@ajato.com.br

${ }^{1}$ Werneck Vianna é o mais destacado defensor deste ponto de vista. Embora seu mais conhecido trabalho (VIANNA, Luiz Werneck. Liberalismo e sindicato no Brasil. 2a ed., Rio de Janeiro: Paz e Terra, 1976) tenha sido

Revista Mundos do Trabalho, vol. 3, n. 5, janeiro-junho de 2011, p. 213-232. 
seria restringir-lhe a qualidade de "livre", chocando-se com a concepção liberal supostamente hegemônica na época.

A imagem do século XIX na França como um período caracterizado pelo predomínio da ideia da legitimidade plena do padrão de laissez-faire nas relações de trabalho fixou-se fortemente na memória histórica de modo geral. No Brasil, foi inteligentemente instrumentalizada na esfera da política pelos vencedores da disputa que desembocou na Revolução de 1930. Lindolfo Collor, ministro do Trabalho de Getúlio Vargas, projetava aquela imagem sobre a da Primeira República, procurando atribuir a esta as características que ele encontrava no período pós-Lei Chapelier na França. Ele dizia, em 1931, na exposição de motivos em favor de um projeto de lei para a instauração de convenções coletivas de trabalho:

Vitoriosa no mundo a mentalidade individualista da Revolução Francesa, passaram as relações entre empregadores e empregados a constituir objeto unicamente de contratos individuais de trabalho. A lei Chapelier de 1791 proibiu toda e qualquer organização de classe. Era a livre concorrência, no campo da produção, corolário da liberdade individual na esfera política. [...] Sob pena de falhar à sua grande destinação coletiva, o Governo criado pela Revolução não poderia deixar de procurar e propor soluções para os nossos problemas sociais, até agora relegados ao mais completo desprezo pelos nossos governos [...]. (Grifos nossos.) ${ }^{2}$

Embora a fala do ministro tenha como foco específico a regulamentação das associações de trabalhadores e de suas relações com o patronato, é para toda a gama das relações de trabalho que se volta sua acusação de abandono dos problemas sociais por parte dos governos da ordem política anterior. A imagem da Primeira República (construída, vê-se, na esfera da política) como um período de hegemonia do princípio de laissez-faire nas relações de trabalho repercutiu bastante na historiografia brasileira. Mesmo com uma visão crítica a respeito daquela imagem, Werneck Vianna, por exemplo, não deixa de ver um liberalismo "ortodoxo" garantido pela Constituição brasileira de 1891 e vigente até 1919 (data da assinatura do tratado de Versalhes pelo governo do Brasil), pelo menos, senão até 1926, quando se dá a reforma da Carta. A imagem foi mantida, no essencial, por outros autores que discutiram o tema das relações de trabalho, como Kazumi Munakata, Michael Hall e Paulo Sérgio Pinheiro, cujas obras mais diretamente ligadas ao assunto - as produzidas nos anos 1980 - não se contrapuseram aos argumentos de Vianna nesse particular e, também nesse particular, permanecem influentes, não tendo sido contraditadas por autores posteriores. ${ }^{3}$

produzido no âmbito da Ciência Política, marcou fortemente o campo dos estudos históricos sobre relações de trabalho na Primeira República e na Era Vargas.

${ }^{2}$ COLLOR, Lindolfo. Contractos collectivos de trabalho -- exposição de motivos. 9/9/1931. Transcrito no Jornal do Commercio de 11/9/1931.

${ }^{3}$ Vianna, Luiz Werneck. Op. cit. MUNAKATA, Kazumi. A legislação trabalhista no Brasil. S. Paulo, $2^{\text {a ed., }}$ Brasiliense, 1984 ( $1^{a}$ ed.: 1981). HALL, Michael M.; PINHEIRO, Paulo Sérgio. Alargando a história da classe operária: organização, lutas e controle. Coleção Remate de Males, n. ${ }^{5}$, 1985, pp. 96-120. 
Contudo, essa visão nos parece bastante discutível, podendo-se, em sentido inteiramente oposto, asseverar que, no Brasil, em momento algum a ideia de laissez-faire logrou hegemonia na esfera das decisões políticas, durante a Primeira República, e que a defesa do princípio de liberdade de trabalho não era então considerada contraditória com a regulamentação legal das relações de trabalho. Não nos deteremos em discutir este ponto, pois foi extensamente abordado em outra publicação ${ }^{4}$; contudo, cumpre lembrar, sucintamene, que os únicos sentidos da expressão "liberdade de trabalho" admitidos legalmente então eram os de liberdade para trabalhar naquilo que se quisesse (artigo 72 , parágrafo 24 da Constituição) e de garantia para se trabalhar sem se ser impedido de fazê-lo por constrangimento de outrem (artigos 204 a 206 do Código Penal, evocados para proteger a "liberdade de trabalho" dos fura-greves). Cabe notar que tais dispositivos legais não proibiam a greve e que este recurso foi amplamente utilizado pelos trabalhadores na época.

Essa reflexão, pela qual nos parece insustentável a visão de que o princípio de liberdade de trabalho fosse um óbice minimamente ponderável à regulamentação do trabalho no Brasil durante a Primeira República, levou-nos a indagar se o significado da ideia de liberdade de trabalho na Lei Chapelier, tal como aparece em diversas obras muito conhecidas da historiografia francesa, também pode ser suscetível de revisão.

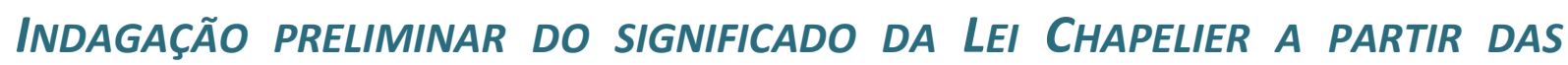 REFERÊNCIAS DO INÍCIO DO SÉCULO XX NO BRASIL, DO SENSO COMUM ATUAL E DA INTERPRETAÇÃO DOS ELEMENTOS INTERNOS DO TEXTO}

Procedemos inicialmente a um exame preliminar do texto da lei, que nos pareceu tornar problemática sua qualificação como instauradora, no âmbito institucional, de um padrão laissez-faire de liberalismo nas relações de trabalho.

Quando, ao terminar a Primeira Guerra, os representantes dos governos que assinam o tratado de paz em 1919 julgam necessário dizer nesse documento que o trabalho não é apenas mercadoria ${ }^{5}$, isso equivale não a negar-lhe o caráter de mercadoria, mas a afirmar que o trabalho deve ter reconhecida sua qualidade de meio de vida do trabalhador e que, por isso, não pode receber o tratamento legal dado à regulamentação da venda de qualquer mercadoria. Com isso, explicita-se o reconhecimento de que o trabalhador é diferente do patrão em forças.

\footnotetext{
${ }^{4}$ A esse respeito, ver: VARGAS, João Tristan. O trabalho na ordem liberal: o movimento operário e a construção do Estado na Primeira República. Campinas: Centro de Memória da Unicamp, 2004.

${ }^{5}$ Traité de paix entre les puissances alliées et associées et l'Allemagne. Partie XIII. Travail. Anexo ao decreto 13.996/12.1.1920, que o promulga. No art. 427, afirma-se o seguinte princípio : “[...] o trabalho não deve ser considerado simplesmente como uma mercadoria ou um artigo de comércio". Todas as traduções de textos em francês, citados a partir daqui, são de nossa responsabilidade.
} 
A interpretação do Tratado pela produção intelectual no século XX certamente fortaleceu a qualificação da Lei Chapelier como texto fundador do liberalismo nas relações de trabalho. O que, para aquela produção, caracterizaria, no tratado de Versalhes, a ruptura da ordem liberal anterior e, por isso mesmo, legitimaria a regulamentação do trabalho é sua recusa a tratá-lo como simples mercadoria. Na Lei Chapelier menciona-se o propósito de defesa da liberdade de trabalho, elemento que nela é focalizado pelos estudiosos. Se temos como pressuposto que o fundamento da ordem anterior era o princípio de liberdade de trabalho e se o tratado, ao reconhecer no trabalho o atributo de meio de sobrevivência, rompe com aquela ordem, isso parece significar que aquele princípio colide com o mencionado atributo. Ou, inversamente, que a ideia de regulamentação do trabalho se choca com a caracterização deste como mercadoria. Assim, a Lei Chapelier, ao declarar o intento de defesa da liberdade de trabalho, estaria em alinhamento perfeito com o princípio liberal de que o trabalho, por ser mercadoria, tem de ser "livre", como livres, na concepção liberal "clássica", devem ser, de modo geral, as mercadorias, salvo exceções determinadas por razões de segurança.

Supondo-se que o trabalho era, na Lei Chapelier, considerado apenas mercadoria, caberia indagar: em que sentido uma mercadoria pode ser livre? Ela só pode ser livre para tornar efetivo aquilo que a define, isto é, para circular no mercado. Por que então aquilo a que foi atribuído o nome de liberdade de trabalho não foi chamado, naquela medida legal, de liberdade de comércio? A expressão "liberdade de trabalho", considerada pelas referências do senso comum atual, parece imprópria para ser empregada no sentido de nãoregulamentação do trabalho, porque implica, entre outras, a ideia de liberdade para o trabalhador optar pelos termos em que pretende trabalhar e, portanto, a de liberdade de unir-se a outros para determinar coletivamente esses termos (o fato de as mencionadas referências pertencerem ao senso comum é uma condição que não lhes diminui em nada a importância, uma vez que são as que mais frequentemente fundamentam a práxis política e que, portanto, mais frequentemente vêm a resultar em medidas práticas). A condição de livre conferida ao trabalho, sendo este fisicamente indissociável da pessoa que trabalha, implicaria a liberdade de o trabalhador se associar, para impedir a queda na escravidão, com a consequente perda da liberdade. Tal ponderação não representa uma simples especulação teórica: trata-se de um elemento presente no debate político. No Brasil, esse parece ter sido o desdobramento que os positivistas fizeram daquela noção de liberdade de trabalho para justificarem o direito de greve ${ }^{6}$. Tal noção, considerada em si mesma, como elemento de argumentação independente, é claramente insuficiente para negar o direito de associação e, até onde chega nosso conhecimento, nunca foi evocada publicamente como fundamento para isso, durante a Primeira República.

Tendo por critério um suposto princípio de liberdade de trabalho, um grupo de indivíduos reunidos no intento de juntar suas decisões individuais a respeito do preço de seu

\footnotetext{
${ }^{6}$ Ver artigo de Teixeira Mendes, o mais destacado intelectual positivista brasileiro, em artigo, de 13.10.1905, reproduzido no diário Comércio de S. Paulo de 28.5.1906, p. 4.
} 
trabalho, se não obrigassem outros trabalhadores a fazerem o mesmo, não estariam tirando a liberdade de estes venderem o seu trabalho pelo preço que quisessem: o direito de greve pacífica, sem constrangimento de outros cidadãos para que a ela adiram, seria admitido, e tal foi o entendimento consensual, declarado, entre os detentores do poder público no Brasil na Primeira República. ${ }^{7}$ A liberdade de trabalho não seria atingida nesse caso.

O grupo de cidadãos que se reúnem para combinar o preço de venda de seu trabalho estaria, sim, constrangendo os compradores de força de trabalho a pagar um preço maior do que se fosse mantida a livre concorrência entre os vendedores. Mas, mesmo aí, nem a liberdade de comércio estaria sendo atingida, porque, no limite, o mesmo raciocínio - pelo qual o ato é indissociável do indivíduo que o pratica - se aplica para a formação de cartéis: se o comércio é livre, um grupo de comerciantes que se reúna para combinar os preços de seus artigos não fere a liberdade de comércio, desde que não obrigue os outros a praticarem os mesmos preços (obviamente, esta é uma postulação puramente teórica, já que, na prática, o acordo pode não fazer sentido se não reunir todos os negociantes de um determinado artigo). As leis coibidoras de cartéis e trustes, vigentes na atualidade em muitos países, não se podem justificar, a rigor, pela defesa da liberdade de comércio, mas, sim, pela defesa do cidadão (seja este o consumidor final ou um industrial ou comerciante) contra a opressão de um grupo.

É claro que, em História, seria absurdo buscar precisão em nomes usados para designar relações e que, ao chamarmos atenção para uma inadequação de termos, queremos apenas destacar indícios que nos digam algo sobre tais relações (o que leva o historiador a investigar o passado é, muitas vezes, seu espanto, o qual com frequência é motivado justamente pela diferença das referências do presente em relação às do passado $\left.{ }^{8}\right)$. O que está em jogo aqui é a definição dos direitos do indivíduo. Esta depende da definição do cidadão. Isto é, os direitos que o cidadão terá depende dos atributos que, na ordem vigente, servem para defini-lo como tal.

Assim, se a expressão liberdade de trabalho é usada para designar a condição que, no liberalismo, deve caracterizar o trabalho enquanto mercadoria, então se trata apenas de um nome específico para a ideia de liberdade de comércio e a liberdade do trabalho é a liberdade da mercadoria. Se os direitos do trabalhador enquanto trabalhador dependem de sua compatibilidade com a liberdade de comércio, então esses direitos são os mesmos atribuíveis ao comerciante. Desse modo, a esfera de cidadania em que se movimenta o trabalhador seria a mesma em que se move o comerciante.

Na lei proposta na Assembleia Constituinte francesa por Le Chapelier, aprovada em junho de 1791, liberdade de trabalho significava liberdade de comércio? Em outros termos, naquele momento o trabalhador foi visto essencialmente como comerciante? Naquele texto, a ideia de que o trabalho é basicamente mercadoria é, de fato, um dos fundamentos

\footnotetext{
${ }^{7}$ A respeito, pode-se ver: VARGAS, J. T. Op. cit.

${ }^{8}$ Embora a ideia em si nada tenha de original, foi Darnton quem a colocou nesses termos. DARNTON, Robert. $O$ grande massacre de gatos e outros episódios da história cultural francesa. Rio de Janeiro: Graal, 2001.
} 
do projeto e, de fato, aparece relacionada à ideia de liberdade de trabalho. Para uma apreciação desse nexo, acompanhemos as mediações que o compõem.

$\mathrm{Na}$ justificação do projeto, a relação entre cidadania e trabalho é colocada em questão e normatizada. Um quadro é afirmado previamente: a relação direta de cada indivíduo, não importa sua condição, com a coisa pública - a cidadania sendo definida por essa relação, a qual é, por sua vez, a um tempo, dependente da afirmação da igualdade geral e sua implicação. Chapelier diz, na justificativa de seu projeto ${ }^{9}$ :

Deve-se, sem dúvida, permitir a todos os cidadãos que se reúnam; mas não se deve permitir aos cidadãos de certas profissões que se reúnam para seus pretendidos interesses comuns. Não há mais corporação no Estado; não há senão o interesse particular de cada indivíduo e o interesse geral. Não é permitido a ninguém inspirar aos cidadãos um interesse intermediário, separá-los da coisa pública por um espírito de corporações. (Grifos nossos.)

Não são admitidos como legítimos os grupos formados por pessoas com interesses específicos comuns, com o objetivo de defender esses interesses. "Certas profissões" quer dizer "profissões específicas": não é permitido aos ouvriers carpinteiros, por exemplo, reunirem-se para defender seus interesses específicos, porque não devem mais existir interesses de grupo, e sim apenas o interesse particular e o interesse geral, que se relacionam diretamente, sem intermediação de espécie alguma.

O cidadão, como indivíduo, deve relacionar-se diretamente com a res publica. Permitir acordos entre indivíduos com interesses determinados (distintos dos dos outros cidadãos) seria permitir a consequente formação de corpos separados dentro da nação, seria separar o cidadão da coisa pública fazendo surgir entre ambos um "interesse intermediário". Chapelier conclui: "É preciso, portanto, remontar ao princípio de que é às convenções livres, de indivíduo a indivíduo, que cabe fixar a jornada para cada operário [...]" (grifos nossos).

Na visão do deputado, só é livre o acordo entre um indivíduo e outro. Acordos entre grupos, ou grupos e indivíduos isolados, não poderiam ser livres: nesse caso, interviria a pressão do grupo, que se destacaria do conjunto da nação ao se arrogar uma norma distinta - um privilégio - que destruiria a igualdade jurídica. Como se nota, o princípio da liberdade está aqui intimamente ligado ao da igualdade.

O objetivo do projeto é "prevenir tanto as coalizões que formariam os operários para fazer aumentar o preço da jornada de trabalho, como aquelas que formariam os empreendedores para fazê-lo diminuir" (grifos nossos). Neste trecho, o operário é considerado como alguém que vende seu tempo de trabalho; o "empreendedor", por consequência, como aquele que o compra. Ambos estão - como indivíduos - ligados pelo

${ }^{9}$ Os trechos da justificativa de Chapelier e do texto legal aprovado, citados a seguir, foram obtidos em: IMBERT, Jean; SAUTEL, Gérard; BOULET-SAUTEL, Marguerite. Histoire des institutions et des faits sociaux ( $\mathrm{X}^{\mathrm{e}}$ XX ${ }^{\mathrm{e}}$ siècle). Paris: Presses Universitaires de France, 1956, p. 279-281. 
mercado de trocas. Sua igualdade é determinada, neste específico relacionamento, por sua condição de agentes naquele mercado. É esta determinada condição que, nesse texto, iguala trabalhadores e patrões, permitindo definirem-se regras iguais para uns e outros. E é somente em atenção a essa condição que tais regras são definidas. Isso não significa porém que, na concepção que embasa o documento, a condição de patrões e trabalhadores seja considerada a mesma. Apesar de fundamentar seu projeto numa noção abstrata de igualdade, Chapelier reconhece que a condição de trabalhador envolve o risco de queda na miséria e na dependência do patrão:

\begin{abstract}
Sem examinar qual deve ser razoavelmente o salário da jornada de trabalho e admitindo apenas que deveria ser um pouco mais considerável do que é no momento [murmúrios], e o que digo neste ponto é extremamente verdadeiro, pois em uma nação livre os salários devem ser suficientemente consideráveis para que aquele que os recebe esteja fora desta dependência absoluta que produz a privação dos artigos de primeira necessidade e que é quase aquela da escravidão.
\end{abstract}

Assim, para Chapelier, se como agente no mercado o operário é igual ao patrão, sua condição não se esgota nessa igualdade: ela implica o perigo de se cair em condição semelhante à de escravo. Chapelier reconhece a necessidade de impedir um rebaixamento do salário que leve o operário à condição de "dependência absoluta". A ideia do trabalhador como vendedor de seu trabalho - correlata à ideia de "locação de serviços", presente, por exemplo, no Código Civil brasileiro de 1916 - não exclui, na formulação de Chapelier, a de um proletariado obrigado pela necessidade de sobrevivência a se submeter a um patrão.

Vê-se que, na lei de 1791, a ideia de "liberdade de trabalho" não era um princípio fundador (isto é, um ponto autossuficiente, que não necessita apoiar-se em nenhum outro, um ponto do qual se desdobrassem outras noções, que para estas fornecesse a base): foi defendida em nome da defesa da condição de cidadão, tanto a do trabalhador quanto a do patrão. A cidadania do patrão (seus direitos como cidadão) estaria ameaçada se fosse permitido imporem-se-Ihe acordos que, baseados em normas que vigessem apenas para determinado grupo de indivíduos, ferissem o princípio da igualdade. O mesmo aconteceria com a do trabalhador caso sua condição fosse aproximada à do escravo devido ao rebaixamento de salários imposto por acordo firmado por um grupo de patrões.

No projeto de 1791, liberdade de trabalho, longe de ser dada como um princípio fundador, é um aspecto da liberdade em geral que o texto propunha fosse assegurado. É um conceito que decorre de outro: a liberdade em geral. Na Constituição francesa de 1791, de cuja elaboração Chapelier participou, declara-se: "Não há mais, para nenhuma parte da Nação, nem para nenhum indivíduo, qualquer privilégio ou exceção ao direito comum de todos os Franceses [...]". ${ }^{10}$ De acordo com a Constituição, todas as instituições que feriam a "liberdade e a igualdade de direitos" teriam de ser abolidas. Não haveria mais, portanto,

${ }^{10}$ IMBERT, J.; SAUTEL, Gérard; BOULET-SAUTEL, M. Op. cit. (Preâmbulo.) 
"corpos judiciais [jurandes] nem corporações de profissões, artes e ofícios". A extinção das corporações (ou "associações", "sindicatos" etc., posteriormente) não se faz em nome de uma distinta "liberdade de trabalho" ou "liberdade de trabalho e indústria", e sim de liberdade em geral (abstrata), fundada na igualdade (igualmente abstrata) - esta, sim, um princípio fundador.

É por isso que Chapelier pode pretender proibir que "os cidadãos da mesma ordem ou profissão, os empreendedores, os donos de oficina aberta, os operários e companheiros de um ofício qualquer" nomeiem presidente, secretários, síndicos, efetuem registros, tomem decisões ou deliberações e constituam "regulamentos a respeito de seus alegados interesses comuns". Nesse caso estariam fundando sua ação e organização em interesses específicos, distintos dos dos outros cidadãos; estariam ferindo o princípio da igualdade e, com isso, o princípio da liberdade. As justificativas das associações operárias para obter autorização de funcionamento - socorrer os doentes e sem trabalho - seriam enganosas porque as caixas beneficentes que para isso eram criadas tenderiam a fazer renascer as corporações. Isso ocorreria por exigirem "a reunião frequente de indivíduos de uma mesma profissão, a nomeação de síndicos e outros funcionários, a formação de regulamentos" e, por esta via, fazerem ressurgir "os privilégios, as maestrias etc." As funções daquelas caixas caberiam ao Estado (Chapelier atribui, aqui, como bem notou Rosanvallon ${ }^{11}$, um papel assistencial ao Estado.) A garantia da liberdade para o trabalho e a indústria é uma decorrência, no texto, da proteção à condição de cidadão, esta, baseada em sua condição de "igual" e, consequentemente, "livre".

A ideia de liberdade de trabalho nem mesmo pode contrapor-se, em princípio (isto é, sem estar relacionada a outras referências), à legislação do trabalho. Chapelier considera operários e patrões iguais enquanto agentes que se relacionam no mercado de trocas - e é para essa relação que propõe a proibição das coalizões, pois são estas que, no texto em questão, atingiriam a liberdade de trabalho.

Tal relação é o foco principal da lei, mas não é o único. Nada na Lei Chapelier autoriza afirmarmos que, na concepção que a fundamenta, a noção de liberdade de trabalho seja contraditória com a ideia de regulamentação do trabalho por meio de leis (contradição que, como vimos, foi vista como traço característico da Primeira República no Brasil). Pelo contrário; pouco mais de uma década depois, em plena vigência da Lei Chapelier, lei posterior, de 12 de abril de 1803 (já da época do Consulado), que pode ser considerada um desdobramento da primeira, trata, em um de seus títulos (o III), justamente "das obrigações entre os operários e aqueles que os empregam". O artigo $9^{\circ}$ aborda os casos em que os contratos de aprendizagem podem ser rescindidos. Um dos ali mencionados é aquele em que "o aprendiz é obrigado a dar, para substituir retribuição pecuniária [pela aprendizagem recebida], um tempo de trabalho cujo valor julgar-se exceder o preço ordinário das aprendizagens". Se o aprendiz for obrigado a ficar mais tempo que o devido, o mestre deve

\footnotetext{
${ }^{11}$ Ver trecho referenciado pela nota 38.
} 
pagar-lhe uma indenização, sendo cada jornada excedente paga ao menos pelo triplo do valor ordinário (art. 10).

São regulamentações mínimas. Boa parte do texto da lei de 1803 é ocupada por dispositivos relativos ao livret para anotações patronais, que tem a "utilidade" também de provar a condição de trabalhador (ou, em outros termos, de obrigar ao trabalho ou, ainda, de restringir os deslocamentos dos pobres): "Todo operário que viaje sem estar munido de uma caderneta desse modo visada [pelo maire ou seu substituto, sendo nela indicado o lugar para onde o trabalhador pretende ir] será reputado vagabundo, e poderá ser punido como tal”. Contudo, forçoso é admitir que a Lei Chapelier, que dá base à de 1803, não pode ser considerada como um documento que funda o princípio da não-intervenção governamental no mercado de trabalho: associações de classe não podem regulamentar as relações de trabalho, mas nada impede que o governo o faça. Nenhum princípio contra essa regulamentação é declarado no preâmbulo ou no corpo da lei. Mais: ao reconhecer a possibilidade de o operário cair em condição semelhante à de escravo por dependência absoluta do patrão e ao excluir a possibilidade de os trabalhadores defenderem-se coletivamente, decorre daí caber ao Estado a proteção do trabalhador contra os abusos do patrão: é este o caso mencionado na lei de 1803 (artigos $9^{\circ}$ e 10) - se o mestre obrigar o aprendiz a ficar além do tempo correntemente admitido para pagar o período de aprendizagem, será obrigado a indenizá-lo. A fixação dessa regra em norma legal, já nos primeiros anos de vigência da Lei Chapelier, por mínima, pífia ou ambígua que seja, é evidência (que não seria indispensável para a conclusão que vem a seguir, mas a reforça) de que aquele papel (a proteção do trabalhador contra os abusos do patrão) faz parte da concepção que fundamenta a mencionada lei.

Tanto a igualdade entre patrão e operário garantida pela lei como meio de impedir a exploração do primeiro sobre o último e (apenas para seguirmos a lógica de Chapelier) viceversa, quanto o auxílio do Estado como meio de impedir a queda na indigência são ilusórios e utópicos. Uma das questões em aberto a respeito dessa medida legal é avaliar-se quanto de utopia radical-burguesa e quanto de intenção de encontrar um meio "legítimo" de submeter, na prática, os trabalhadores aos patrões poderia haver no ato de propô-la. Ambas parecem combinar-se na produção do mesmo efeito (ainda que porventura não coincidissem no espírito do autor da medida). Contudo, seria miopia de nossa parte (como já pareceu a Jaurès ${ }^{12}$ ) acreditarmos que o texto representava apenas a expressão direta de interesses patronais. Parece-nos bastante possível que, por um lado, nas condições de acirrado embate entre facções políticas na época, o grupo então dominante acreditasse prioritário, para manter-se como tal, prevenir o aparecimento de focos de contestação em associações operárias e que, por outro, houvesse uma real intenção, da parte de muitos dos que apoiaram a medida, de realizar a utopia da relação direta cidadão/coisa pública, central num projeto de nação que pretendia abolir as corporações e seu "espírito".

${ }^{12}$ Ver adiante. 
Contudo, ante a ultrarregulamentação do trabalho e da atividade econômica em geral no Antigo Regime, a Lei Chapelier não implicaria, na prática, uma desregulamentação? Sem dúvida. Porém, com isso, no período que ela inaugura, a legitimidade da regulamentação não desaparece, mas se coloca em outro registro, em outro contexto, com outras significações: é a regulamentação dentro do liberalismo. Se esta formulação parece paradoxal, devemos afirmar que não é senão uma decorrência do caráter que identificamos na Lei Chapelier, que, de fato, deve ser reconhecida como fundadora de um novo período (o qual, porém, como se pode observar, tem um sentido muito diferente daquele que usualmente lhe é atribuído).

Para entendermos a diminuta dimensão da regulamentação do trabalho presente na mencionada lei de 1803, um dado que deve ser levado em conta (embora não seja o único) é o quadro histórico da indústria na época, na França: o trabalho é, em muito larga medida, artesanal, feito em pequenas oficinas ou em domicílios rurais; seu parcelamento entre diversos indivíduos, quando ocorre, é bem reduzido; mecanização na indústria, a custo enxergá-la-íamos em caráter excepcional e localizado. A variedade de situações de trabalho não-agrícola é considerável. O ouvrier daquele tempo não é, de modo algum, o operário da indústria moderna. Compreende-se que, nessas condições, a ideia de criar-se regras legais gerais para o trabalho não se colocasse enfaticamente. Seria um canhestro anacronismo esperarmos encontrar num texto francês do final do século XVIII ou início do XIX uma proposição de leis de trabalho que sequer lembre as reivindicações de operários de meados do século XIX ou do século XX: as relações de trabalho eram muito outras.

Tudo considerado, não se pode deixar de concluir que, para Chapelier, se o operário era igualado ao patrão enquanto agente no mercado de trocas, isto é, enquanto vendedor (de força de trabalho) e, por isso, nesse aspecto de suas relações com o patrão, deveria respeitar regras válidas igualmente para este, tal qualidade (de agente no mercado) não esgotava a condição de operário, uma vez que se reconhecia nesta última o risco de queda na dependência absoluta do comprador da força de trabalho.

Aceitos os passos assinalados até aqui, impõe-se a conclusão: a Lei Chapelier não inaugura no plano institucional um regime de laissez-faire nas relações de trabalho nem representa um momento em que tal concepção houvesse logrado hegemonia. Admitir isso implica aceitar que a proibição de associações operárias não é contraditória, em princípio, com uma ordem institucional da qual não se excluam medidas governamentais de proteção ao trabalhador - em outros termos, uma ordem que não exclua a ideia de regulamentação das relações de trabalho.

Isso não quer dizer que a ojeriza a leis de trabalho não houvesse aparecido explicitamente em falas diversas no período aqui abordado, nem que patrões, indiferentes a qualquer debate a respeito do assunto ou mesmo a quaisquer medidas governamentais porventura aprovadas, não se tivessem aproveitado de um regime de fato de laissez-faire em suas relações com a mão de obra (neste ponto, falamos do contexto francês, mas o mesmo pode ser dito com relação ao brasileiro). O termo escolhido no nível institucional 
para objeto de discussão aqui não significa que acreditemos bastar o estudo de leis, decretos etc. para entender-se as relações efetivamente existentes num determinado momento histórico; é óbvio porém que o decidido naquele nível representa um importante indício dessas relações e não pode ser desconsiderado.

Vale acrescentar que obras como a de Adam Smith ${ }^{13}$, por mais visibilidade e aceitação que tenham tido, não representam senão projetos - que, no caso do economista escocês, podem ser considerados em boa medida utópicos ${ }^{14}$. Contudo, talvez devido justamente àquela visibilidade, tais textos acabaram por compor um contexto no qual dão o tom, o qual até os dias atuais se impõe no campo dos estudos históricos como o fidedigno retrato da realidade.

A partir dessas ponderações preliminares, passamos a considerar as avaliações da Lei Chapelier existentes na produção intelectual que focalizou especialmente a Revolução Francesa.

\section{A Lei Chapelier na produção intelectual do século XX}

O autor que mais se deteve sobre a Lei Chapelier continua sendo Jaurès, em sua obra do início do século $X X^{15}$. É, por esse motivo, o que mais ganha espaço em nossas considerações.

Comentando um pedido de empreiteiros por medidas para reprimir movimento de carpinteiros que se dava na ocasião em que se discutia a lei, Jaurès aponta o caráter de classe desta, nascida, segundo ele, para atender aos interesses dos primeiros. A "grande burguesia dos empreendedores [entrepreneurs]", diz ele, "pretende que a coalizão dos assalariados falseie a concorrência, e que esta deve exercer-se de indivíduo a indivíduo sem que os proletários possam agrupar-se". Assim, conclui : "Portanto, era bem em meio a uma primeira luta entre assalariados e capitalistas, que a Constituinte se pronunciava pela Lei Chapelier: e é impossível não reconhecer a origem de classe desta lei" ${ }^{16}$.

Em face desse significado, diríamos (procurando aqui tornar explícita uma concepção que o autor mantém implícita), objetivo, da lei, Jaurès registra seu espanto pelo fato de Marat, Robespierre e outros participantes da cena política que mantinham algum tipo de

\footnotetext{
${ }^{13}$ SMITH, Adam. A riqueza das nações: investigação sobre sua natureza e suas causas. São Paulo: Abril, 1983. 2 v.

${ }^{14}$ Referindo-se a outro contexto, o do mercado de cereais no século XVIII, Thompson qualifica o modelo de Smith (de "uma economia natural e auto-reguladora, funcionando providencialmente para o bem de todos") como "supersticioso". O termo parece ter sido utilizado devido à comparação que Thompson faz do modelo laissez-faire com o modelo paternalista, qualificado daquela mesma forma por Adam Smith. THOMPSON, E. P. Costumes em comum: estudos sobre a cultura popular tradicional. São Paulo: Companhia das Letras, 1998, p. 160-164.

${ }^{15}$ JAURÈS, Jean. Histoire socialiste de la Révolution Française. La Constituante. [190?] A obra aparece em vários volumes, de 1901 a 1904. A tradução dos trechos que citamos a seguir é nossa.

${ }^{16}$ Op. cit., p. 621.
} 
vínculo com os franceses pobres não terem reconhecido aquilo que vê como o significado fundamentalmente social e econômico e, por essa via, político - da medida. Ele cita Marat (L'Ami du Peuple, 18/6/1791):

Enfim, para prevenir os ajuntamentos numerosos do povo que tanto temem, eles ["os representantes das ordens privilegiadas"] retiraram à classe inumerável dos ajudantes de pedreiros e dos operários o direito de se reunir, para deliberar em ordem sobre seus interesses, sob o pretexto de que esses homens reunidos poderiam ressuscitar as corporações que foram abolidas.

Eles não queriam senão isolar os cidadãos e impedi-los de ocupar-se em comum da coisa pública.

Comentário de Jaurès:

Assim, para Marat, advertido no entanto pela luta social dos mestres pedreiros e
seus operários, a lei de 14 de junho é apenas uma das medidas (e sem dúvida a
menos importante) dirigidas pelo realismo e o moderantismo contra a nação. É
apenas uma arma forjada pelos amigos do antigo regime contra as liberdades
novas da nação. Marat não acusa a Constituinte de impedir as reuniões e os
entendimentos de operários para manter salários baixos. Acusa-a de dispersar
cidadãos que se reúnem para defender a liberdade pública. Ele mesmo, como se
fizesse de conta, não reconhece e apaga o caráter social da lei, e lá onde Marx
denuncia um golpe de Estado burguês, Marat vê apenas uma manobra da Contra-
Revolução. Ele não supõe um minuto que os operários pudessem, nas reuniões,
ocupar-se de seus interesses de classe: mas é, segundo ele, porque eles ali se
ocupariam em comum da coisa pública (grifos de Jaurès) que a Assembléia os $_{\text {proíbe }{ }^{17} \text {. }}$

Tal explicação da fala de Marat como expressão de um descolamento entre a consciência e a realidade (o qual, de nosso lado, incluiríamos entre as "defasagens" apontadas no livro de Jaurès por Ozouf, em ensaio que discutimos à frente) não satisfaz nossas interrogações. Parece-nos difícil aceitar que Marat não tenha visto o significado social da lei, considerando-se que, na edição de 12/6/1791 de seu jornal, ele mesmo publicou uma carta (de que tomamos conhecimento pelo próprio livro de Jaurès), datada de 8/6/1791, atribuída aos operários carpinteiros, na qual se apontava a iniciativa dos empreiteiros de se dirigir à Assembleia Constituinte para obter uma lei contra eles ${ }^{18}$.

Se foram os operários que redigiram o texto (o que parece improvável), ou se foi o próprio Marat que o fez, não importa: sua presença no Ami du Peuple é mais uma evidência de que Marat não separa as associações operárias de seu objetivo de defesa de interesses específicos de uma categoria. O próprio Jaurès dizia, para realçar seu espanto com a atitude do publicista, que "ele conhecia muito bem o conflito entre os empreendedores e os operários: e ele tinha tomado partido claramente pelos operários"19.

Duas possibilidades de interpretação colocam-se aqui:

\footnotetext{
${ }^{17}$ Op. cit., p. 615-616.

${ }^{18}$ Op. cit., p. 612.

${ }^{19}$ Op. cit., p. 612.
} 
1) Marat propõe-se a defender os interesses de classe dos operários; para fazê-lo, precisa articular os elementos de sua argumentação com um dos valores consensuais no momento: a defesa da coisa pública (mais precisamente, do espaço democrático). Para defender seus pontos de vista, ele precisa articulá-los com os elementos valorizados consensualmente dentro de uma esfera na qual se pretende a interlocução (o que é válido para qualquer época).

2) Marat interessa-se em primeiro lugar pela defesa do espaço democrático; o foco principal de sua atenção não está nos interesses dos operários, os quais nem por isso deixa de reconhecer, mas no significado de suas associações ou reuniões como locais onde se pode discutir a coisa pública.

Vê-se que as duas possibilidades implicam a não-excludência recíproca de, por um lado, defesa de interesses específicos de uma categoria e, por outro, de defesa da esfera democrática. O que parece estar fora de dúvida é a necessidade de, para compreender as atitudes e palavras de Marat (ou de qualquer outro ator na cena política da época), levarmos em conta suas relações com a esfera de consenso na qual se movia.

Segundo Jaurès, Marat não vê o significado social da lei. Uma outra leitura da fala de Marat nos leva a concluir que, inversamente, é Jaurès que não vê aquilo que Marat vê, porque dá como excludentes elementos que, no discurso de Marat, convivem lado a lado, por serem por este considerados compatíveis: a defesa de interesses específicos de uma categoria de trabalhadores (os operários da construção) e a defesa da coisa pública. Afinal, dizer que ele "não supõe um minuto que os operários pudessem, nas reuniões, ocupar-se de seus interesses de classe", ante o fato de que Marat menciona, explicitamente, o direito de os operários se reunirem "para deliberar em ordem sobre seus interesses" só é possível optando-se pela hipótese de que ele considerasse tais interesses não os específicos da categoria, mas os da nação, interpretação que é, no mínimo, discutível. A época de Jaurès é outra: a esfera de consenso em que se coloca sua fala é outra; os elementos de consenso da esfera anterior parecem perder relevância em face daqueles que gostaria de ver enfatizados.

Também é motivo de espanto para Jaurès o "silêncio completo" de Robespierre para com a lei. Seria impossível que alguém que "se apoiava antes sobre o povo dos artesãos e operários que sobre a burguesia industrial" e defendia a distribuição de armas (e a concessão do direito de voto) a todos os cidadãos, não apenas os ativos (lembrando-se que a burguesia, para Jaurès, "teme mais o armamento geral do povo que o direito de coalizão"), não tivesse apreendido o significado da Lei Chapelier, ainda mais levando-se em conta que Robespierre havia, pouco mais de um mês antes, defendido o direito de petição coletiva, contra a posição de Chapelier de só permitir petições individuais. O direito de coalizão, pondera Jaurès, é o "prolongamento econômico" do direito de petição coletiva: o primeiro é "a ação coletiva dos pobres na ordem econômica", enquanto o último é "sua ação organizada na ordem política". Se Robespierre, defensor do direito de petição coletiva, não se manifestou quanto à Lei Chapelier, seria porque, não vendo "o imenso movimento econômico burguês" do qual a Revolução, dada por ele como obra dos pobres, era a 
conclusão, "não pressentiu aquela luta que ia nascer na indústria capitalista". A importância da lei lhe teria sido ocultada pelo predomínio da pequena indústria na época. Uma hipótese que levanta para explicar sua atitude é a de que teria concordado com a ideia de que a permissão para formar coalizões seria um passo para o restabelecimento das corporações ${ }^{20}$.

Assim, Jaurès nega que os principais atores políticos (incluindo o próprio autor da lei, como indicamos abaixo) tenham visto a importância econômica da medida. Não nos satisfaz, como dissemos acima, a explicação das atitudes de Marat, Robespierre e outros pela ideia de uma distância entre a consciência dos contemporâneos e os deslocamentos e tendências da realidade social e econômica de sua época, que os teria levado a não avaliar com precisão os efeitos de uma medida legal. Nossa experiência de pesquisa nos impele a acreditar que nós, historiadores, é que não conseguimos identificar aquilo que os contemporâneos viram e que conferia coerência a suas atitudes. Contudo, a visão de Jaurès, que o conduz à perplexidade e, por essa via, à indagação, parece-nos, mais de cem anos depois, mais frutífera do que a apreciação da atitude de Robespierre feita por Patrice Gueniffey no final do século XX. Esta autora, explicando as atitudes de Robespierre por sua preocupação em sempre manter sintonia com a conjuntura, diz que "suas convicções sociais não apresentavam mais coerência do que as políticas" e isto lhe basta para explicar por que "não teve qualquer participação" no debate sobre a Lei Chapelier. Sua atenção estaria voltada para o espaço da política, não para a realidade social: "O povo ao qual Robespierre dedicou sua vida descia à rua para exigir a cabeça dos conspiradores, nunca para reclamar pão" ${ }^{21}$. De fato, por essa via, não há do que se espantar na atitude do jacobino: nada mais há a interrogar aí.

O ponto de vista de Jaurès o leva a espantar-se com o que vê como, diríamos, uma avaliação "por baixo" da Lei Chapelier por parte de Marat e Robespierre; esse mesmo espanto parece tê-lo impelido a uma apreciação mais detida das atitudes e discursos da época, o que resultou numa qualificação original para a figura de Chapelier: "individualista estatista". Por ela opta após avaliar seu combate (que vê como sincero) a toda forma de corporação e agrupamento: Jaurès menciona como exemplo a luta de Chapelier contra as corporações eclesiásticas. Sua intolerância aos agrupamentos não se vincularia a uma preocupação de classe. Tanto que Jaurès aventa a possibilidade de que Chapelier, "no interesse da liberdade individual e para fazer cair a escravidão dos salários demasiado baixos", pudesse aceitar a intervenção do Estado na fixação de um salário mínimo ${ }^{22}$.

Se, para Jaurès, a concepção de Chapelier de que os indivíduos devem relacionar-se diretamente com o Estado, sem agrupamentos intermediários, servia aos interesses da burguesia, ele não aceita como algo demonstrado que tivesse sido "sobretudo para desarmar o proletariado" que Chapelier propôs a lei de 14 de junho. A linguagem de Marat já lhe havia parecido "a prova decisiva" de que a medida "não encerra, no grau em que

\footnotetext{
${ }^{20}$ Op. cit., p. 611.

${ }^{21}$ GUENIFFEY, Patrice. Robespierre. In: OZOUF, Mona. Jaurès. In: FURET, François; OZOUF, Mona. Dicionário crítico da Revolução Francesa. Rio de Janeiro: Nova Fronteira, 1989 (1 ${ }^{a}$ ed., em francês: 1988), p. 320-321.

${ }^{22}$ JAURÈS, J. Op. cit., p. 608.
} 
acreditou Marx, intenções de classe ocultas": "o conflito econômico nascente entre os burgueses e os proletários era pouco compreendido". O "alcance futuro da lei" não teria sido apreendido pelos contemporâneos. A propósito, Jaurès registra que, afora L'Ami du peuple, os outros jornais da época, comprometidos ou não, em alguma medida, com os pobres, silenciam sobre a Lei Chapelier ${ }^{23}$. Jaurès aventa a hipótese de que a "burguesia revolucionária" não havia previsto todo o uso que o capital poderia fazer da lei ${ }^{24}$.

Jaurès agrega a seu espanto com a atitude dos contemporâneos ante a Lei Chapelier o estranhamento com a fala dos primeiros historiadores "da burguesia", que parecem "ter ignorado completamente" a medida. O exemplo que dá é Thiers (Histoire de la Révolution Française), de quem cita a seguinte frase, a propósito da situação criada com a depreciação dos assignats:

O povo operário, sempre obrigado a oferecer seus serviços, dá-os a quem os quer aceitar, não sabendo concertar-se para fazer aumentar os salários pelo dobro, pelo triplo, à medida que os assignats diminuíam na mesma proporção, recebia apenas uma parte do que lhe era necessário para obter em troca os objetos de suas necessidades. (Grifos de Jaurès.)

Explicando seu juízo sobre aqueles historiadores, Jaurès pondera que Thiers, na citação acima, teria de estar fazendo uma ironia "demasiado grosseira" caso realmente soubesse que existia uma lei da Constituinte proibindo justamente aquela coalizão da qual ele reputava os trabalhadores incapazes na época. Neste ponto, deveríamos, de nosso lado, ponderar: Thiers, que de modo algum se destacava por uma ausência da vida política, por um desinteresse dos negócios públicos, ignoraria que aquela lei ainda vigorava? 0 estranhamento com a ausência da Lei Chapelier no texto de Thiers é um bom ponto de partida. Porém, em vez de tomarmos o caminho de Jaurès, parece-nos que devemos ir no sentido inverso e nos perguntarmos o quê, na ordenação social da França das primeiras décadas do século XIX, aquela ausência indica. Parece-nos ser aqui o caso de se indagar em que medida tal lei de fato era aplicada e de fato tinha importância no contexto da época. Essa é uma questão que, apesar de todo o dilúvio de tinta já despendido no comentário da herança da Revolução Francesa, permanece não satisfatoriamente respondida.

Se o silêncio de Thiers nos parece muito significativo, o do socialista Louis Blanc também apontado por Jaurès - mostra-se, forçosamente, ainda mais eloquente ("Coisa ainda mais curiosa!", diz ele, "Louis Blanc ignora completamente a existência da lei Chapelier." ${ }^{25}$ ). O primeiro, à época em que publicou seu livro, ainda não havia assumido nenhum cargo político de maior importância, como viria a fazer até o final de sua vida; o último, durante o período em que foram aparecendo os seis volumes de sua obra (Histoire de la Révolution), compreendido pelos anos 1847-1862, veio a fazer parte, como se sabe, do

\footnotetext{
${ }^{23}$ Op. cit., p. 613.

${ }^{24}$ Op. cit., p. 616.

${ }^{25}$ Op. cit., p. 616.
} 
governo surgido da revolução de 1848, que chegou a manter certa interlocução com os operários franceses. Qual seria o motivo de, no final da década de 1840, a Lei Chapelier ser tão indiferente para pessoas tão comprometidas com as lutas sociais como Louis Blanc?

Se essa indiferença não se explica por uma defasagem entre a consciência e a realidade (pois o compromisso com as lutas sociais, seja qual for, implica razoável grau de conhecimento da "realidade" em que aquelas ocorrem), obrigatoriamente a explicação para isso deve ser buscada na consideração daquelas pessoas a respeito do tratamento institucional dado aos movimentos de trabalhadores. Um estudo das diversas visões registradas na primeira metade do século XIX a respeito de tal tratamento - que incluiria necessariamente as ponderações sobre a Lei Chapelier - talvez trouxesse novo significado às medidas, derrogativas daquela lei, surgidas apenas cerca de quinze anos depois (em 1864) do texto de Louis Blanc estudado por Jaurès. Na atualidade, mantém-se a visão de que a lei de 1791 inaugura um período não só de interdição total da greve, como também de afirmação institucional do princípio de total "liberdade" contratual nas relações de trabalho.

Cerca de duas décadas depois da publicação dos volumes de Jaurès, Henri Sée chama atenção para o fato de a Lei Chapelier colocar-se numa linha de continuidade com práticas do Antigo Regime. Ao longo do século XVIII, frequentemente eram baixadas medidas contra associações de compagnons: o Estado, que tendia a relaxar os regulamentos de fabrico, vai tornando mais estrita a regulamentação das relações de trabalho, com a finalidade de vincular mais estreitamente o operário ao patrão. As sociedades de socorros mútuos são vistas com desconfiança: crê-se que sirvam de cobertura para o funcionamento de sociedades de resistência. Contudo, Sée observa (sem maior discussão) que a Lei Chapelier não deixa de estar também em coerência com as doutrinas econômicas do século XVIII ${ }^{26}$.

Esmein, em livro aparecido em $1911^{27}$, havia procurado mostrar a coerência da Lei Chapelier com o anterior decreto de 2 de março de 1791 que, abolindo as maîtrises, proclamava a liberdade de trabalho, de comércio e de indústria. A lei de 14 de junho, ao proibir toda associação entre operários ou entre patrões, atenderia à necessidade de assegurar a existência real da liberdade de trabalho: seu objetivo seria garantir o direito individual; o indivíduo não poderia lutar eficazmente contra associações que lhe quisessem regulamentar suas condições de trabalho e de salário. A essa preocupação, ter-se-ia somado o temor de que, "pelo jogo dos contratos" (termos de Esmein), as antigas organizações fossem reconstituídas. Essa medida contra a liberdade de associação e de greve é qualificada pelo autor como "erro" cometido pelos homens da época. O uso do qualificativo indica a intenção de mostrar que a medida não se devia a uma parcialidade em favor de interesses materiais, mas a um equívoco provocado pela vontade de coerência.

${ }^{26}$ SÉE, Henri. L'évolution commerciale et industrielle de la France sous l'Ancien Régime. Paris: Félix Alcan, [192?], p. 345-357.

${ }^{27}$ ESMEIN, A. Précis eleméntaire de l'histoire du droit français de 1789 à 1814: Révolution, Consulat \& Empire. Paris: Recueil Sirey, 1911, p. 185-188.

Revista Mundos do Trabalho, vol. 3, n. 5. 
Mathiez, na década de 1920, apenas menciona a Lei Chapelier. Sem nenhuma tentativa de explicação, a medida aparece no âmbito de uma narrativa das consequências da crise dos assignats, em seguida à menção à ocorrência de numerosas greves. Uma vez que fala da agitação como tendo tomado "manifestamente os caracteres de uma luta de classes", a impressão que temos é a de que considera a lei como um episódio desta última ${ }^{28}$.

Em livro aparecido no final daquela década, Gaxotte, no outro extremo do espectro político, também vê a lei como resposta às greves e faz um comentário: "Pode-se dizer que todo o sindicalismo contemporâneo é uma insurreição contra a lei Chapelier" ${ }^{29}$.

Lefebvre, em 1930, cita de forma muito sucinta a medida, em item dedicado à "obra econômica" da Constituinte, no qual comenta a atenção dada ao proletariado: "[...] absolutamente não se pensou nele, a não ser para confirmar, em 14 de junho de 1791, pela lei Le Chapelier, a proibição das associações de operários e da greve" ${ }^{30}$.

Soboul, no início da década de 1960, dá a Lei Chapelier como uma simples expressão do liberalismo econômico, definido pelo princípio de laissez-faire: "A liberdade de trabalho, num tal sistema [em que as forças capitalistas de produção deviam estar libertas], está indissoluvelmente ligada à liberdade de empresa: o mercado de trabalho deve ser livre como o da produção [...]". A proibição da coalizão e da greve operárias teria constituído "uma das peças mestras do capitalismo da livre concorrência", de modo que "o liberalismo, fundamentado na abstração de um individualismo social igualitário, beneficiava os mais fortes" ${ }^{\prime 3}$.

Cobban, em texto editado em 1964, preocupado em retirar substância à visão pela qual a Revolução teve caráter de ruptura e de inauguração de um período de desenvolvimento das forças produtivas, focaliza, no caso da Lei Chapelier, as linhas de continuidade com o Antigo Regime. Cita comentário de Braesch segundo o qual identificá-la como uma medida revolucionária, de defesa dos interesses burgueses contra os dos trabalhadores, seria apreciá-la por critérios modernos. Menciona também o trabalho de Sée (supracitado), que teria salientado "o fato de ela se limitar a repetir a legislação do ancien régime", o que, notemos de passagem, não corresponde com a devida precisão ao ponto de vista daquele autor: Sée, como fizemos notar acima, vê na Lei Chapelier também coerência com o pensamento liberal do século XVIII. ${ }^{32}$ Cobban não se detém muito mais na identificação do significado da medida para os contemporâneos e pósteros. A Lei Chapelier aparece apenas, de modo bastante fugaz, como um entre os numerosos exemplos apresentados em apoio a sua visão geral.

\footnotetext{
${ }^{28}$ MATHIEZ, Albert. La Révolution Française. Paris: Armand Colin, 1963, p. 153. Os três volumes da obra foram editados pela primeira vez entre 1921 e 1927.

${ }^{29}$ GAXOTTE, Pierre. La Révolution Française. Paris: Fayard, 1975, p. 170. A primeira edição é de 1929.

${ }^{30}$ LEFEBVRE, Georges. A Revolução Francesa. São Paulo: Ibrasa, 1966, p. 162.

${ }^{31}$ SOBOUL, Albert. A Revolução Francesa. Rio de Janeiro: Zahar, 1964 (1 ${ }^{a}$ edição: 1962), p. 165-166.

${ }^{32}$ COBBAN, Alfred. A interpretação social da Revolução Francesa. Lisboa: Gradiva, 1988, p. 75-76. BRAESCH, Fréderick. 1789, I'année cruciale. Paris: Gallimard, 1941, p. 251. SÉE, Henri. Op. cit.
} 
Furet e Richet, em sua conhecida obra conjunta sobre a Revolução, não trazem nenhum ângulo novo para o tema; pelo contrário, apresentam a Lei Chapelier como em sintonia perfeita com o liberalismo econômico: "[...] rigorosamente fiel ao esquema liberal, a lei Le Chapelier exclui o sindicalismo da vida social, estendendo o imperialismo do contrato burguês ao mundo do trabalho." Interpretam, mesmo, parecendo nisto ignorar as perplexidades de Jaurès, como "um sinal dos tempos" (tempos de hegemonia ideológica do liberalismo) o fato de que "ninguém, à esquerda da Constituinte, se levanta para defender o direito dos assalariados à coalizão" ${ }^{33}$.

Ao que sabemos, Furet não se ocupa do tema em obras posteriores. O item parece ocupar diminuto e secundário espaço em suas preocupações: um dos motivos por que considera que "não é essencial" criticar as interpretações que reduzem a dinâmica política da Revolução Francesa às oposições sociais, mostrando "suas incoerências em relação aos dados estritamente sociais do problema", é o de "essa crítica já ter sido feita, especialmente por Cobban" ${ }^{34}$. Conclui-se que, em sua concepção, as conclusões deste não alteram a visão que ele e Richet apresentam na obra mencionada acima. Em confirmação a isso, temos, no Dicionário crítico sobre a Revolução Francesa, elaborado sob a direção de Furet e Mona Ozouf, um ensaio de Patrice Higonnet sobre os sans-culottes que vê "um contraste muito nítido entre o individualismo radical da lei Le Chapelier e o papel social do Estado neutro, tal como o concebiam os Feuillants" ${ }^{35}$.

Num estudo de Mona Ozouf (presente no mencionado Dicionário) sobre a obra de Jaurès, as ponderações deste a respeito da Lei Chapelier ganham, embora de forma resumida, grande destaque, pois são justamente o exemplo apresentado pela autora para indicar "o que os proletários devem [...] reter dessa história 'socialista"”: "que a luta de classes não é um mecanismo que tudo explica ou que tudo produz". Para Jaurès, lembra a autora, à medida não deveria ser conferida "a brutalidade que lhe deram os antagonismos ulteriores", já que "nem para Chapelier, nem para os constituintes que a votaram por unanimidade, animados pelo individualismo estatal que faz odiar as corporações e os agrupamentos, não tinha a lei por objetivo desarmar o proletariado" ${ }^{36}$.

Surpreende-nos, no comentário de Ozouf, a serena menção à ideia de individualismo estatal, sem aspas. Expressão, no mínimo, curiosa, que parece ter sido criada por Jaurès para dar conta provisoriamente de uma atitude - de Chapelier, não dos constituintes em geral, como faz supor a autora - para a qual não encontra explicação que lhe satisfaça plenamente, aparecendo contudo sem nenhuma problematização na fala de Ozouf.

\footnotetext{
${ }^{33}$ FURET, François; RICHET, Denis. La Révolution française. Paris: Fayard, 1973. p. 122. A primeira edição é dos anos 1965-1966.

${ }^{34}$ FURET, François. Pensando a Revolução Francesa. Rio de Janeiro: Paz e Terra, 1989 (1 ${ }^{a}$ ed., em francês: 1983), p. 67. Podem-se consultar também: FURET, F; OZOUF, M. Op. cit.; FURET, F. Ensaios sobre a Revolução Francesa. Lisboa: A Regra do Jogo, 1978 (o conteúdo deste livro coincide parcialmente com o da primeira obra citada nesta nota). FURET, F. Marx e a Revolução Francesa. Rio de Janeiro, Zahar, 1989 (1 ${ }^{\text {a }}$ ed., em francês: 1986).

${ }^{35}$ HIGONNET, Patrice. Sans-culottes. In: FURET, François; OZOUF, Mona. Op. cit., p. 414.

${ }^{36}$ OZOUF, Mona. Jaurès. In: FURET, François; OZOUF, Mona. Op. cit., p. 998.
} 
Pierre Rosanvallon, em obra publicada em $1981^{37}$, traz um ponto de vista inteiramente original: a Lei Chapelier, afirmando a exclusividade da relação entre o interesse particular de cada indivíduo e o interesse geral, e por esse motivo banindo as associações intermediárias entre um polo e outro, seria a pedra fundamental do Estado-providência. Tal Estado, cuja característica distintiva seria a finalidade de compensar a desigualdade social, só se teria tornado possível pela afirmação do indivíduo "total", "integral", que se opõe a toda forma de solidariedade ou sociabilidade tradicionais, como as religiosas, corporativas ou comunais. Esse indivíduo é aquele que a Lei Chapelier procura criar: "Uma concepção estatal da assistência é o corolário do individualismo o mais radical em matéria de relações sociais".

Citando o relatório de Émile Ollivier a respeito da lei de 25 de maio de 1864, a qual anulava a medida de 1791, Rosanvallon chama atenção para a importância que, naquele documento, assume o papel, que Chapelier atribui ao Estado (a Nação), de fornecer trabalho àqueles que dele têm necessidade para viver, além de prover socorros aos enfermos. 0 parlamentar, apontando a articulação deste item com o princípio, mencionado acima, da relação direta entre o indivíduo e o Estado, vê na concepção aí expressa o "erro fundamental" da Revolução Francesa. Daí se teria originado a concepção do Estadoprovidência, a "extensão desmesurada dos direitos sociais", as "exagerações dos reformadores socialistas", entre outros elementos que the parecem condenáveis. Rosanvallon conclui que a permissão para as associações, presente na lei de 1864 , teria sido o alvitre para fornecer uma alternativa ao Estado-providência: "o meio, temporário, de limitar o crescimento do Estado".

Coerentemente, o autor aponta uma contradição entre a afirmação do princípio individualista pelo liberalismo do século XIX e sua atitude de repelir a ideia de intervenção do Estado na esfera social. A revogação da Lei Chapelier teria sido uma tentativa de sanar essa contradição. Assim, para que esta última pudesse ser superada, os liberais tiveram de abrir mão de sua hostilidade às associações operárias.

Trata-se de uma visão sem dúvida nenhuma muito frutífera; contudo, o autor diz que o motivo da aversão às associações operárias era o intento de preservar a liberdade de trabalho. De acordo com toda a tradição historiográfica discutida no presente artigo, o princípio da liberdade de trabalho tem na Lei Chapelier um momento de afirmação formal. Já fizemos notar que, a nosso ver, nesta medida legal, aquele "princípio" não era contraditório com a intervenção do Estado nas relações de trabalho. Rosanvallon não se posiciona a respeito das relações entre a Lei Chapelier e a possibilidade da aprovação de leis de trabalho, como limitação da jornada, férias etc. Seu foco é a seguridade social (aposentadoria, assistência médica, seguros contra acidentes etc.), que em medida considerável implica o uso de fundos públicos, e a crise de legitimidade que atingia as propostas de sua expansão na época da elaboração do livro. Sua abordagem da Lei Chapelier

${ }^{37}$ ROSANVALLON, Pierre. La crise de l'État-providence. Paris: Seuil, 1981, p. 44-46. 
dá-se a partir dessa problemática. Assim, o que destaca na revogação da lei em 1864 é o intuito de livrar o Estado da obrigação de prover à seguridade, transferindo-a às associações operárias. O autor não se coloca quanto ao significado de "liberdade de trabalho" na lei de 1791: caso considerasse que este é o mesmo que o dos liberais que, em sua visão, no século XIX se opunham à intervenção do Estado nas relações de trabalho, a contradição, citada acima, que aponta no liberalismo, deveria ter sido identificada no próprio texto daquela medida legal. Sabe-se que, na lei de 25/5/1864, a ideia de "liberdade de trabalho" não era contraditória com greve ou associação de trabalhadores: tal como no Brasil da Primeira República, era entendida como o direito de trabalhar sem constrangimento de outros para que se deixe de fazê-lo em razão, por exemplo, de movimento reivindicatório. Que mediações se colocaram historicamente, no plano das representações sobre as relações de trabalho, entre o entendimento de liberdade de trabalho na Lei Chapelier e seu significado na lei de 1864 ? Que alterações esses deslocamentos acarretaram nos nexos entre igualdade e liberdade ${ }^{38}$ São questões ainda sem resposta satisfatória.

Em conclusão, após o exame da documentação e do debate historiográfico que, direta ou tangencialmente, dizem respeito à Lei Chapelier, permanecem as seguintes constatações:

- tal lei não pode ser dada, como tem feito parte representativa da produção acadêmica francesa e brasileira, como um texto fundador do liberalismo nas relações de trabalho, sem maior problematização;

- seu significado para os contemporâneos permanece em aberto;

- mesmo se dá com o significado da Lei Chapelier para as relações entre patrões e trabalhadores no século XIX.

Recebido em 15/03/2010

Aceito para publicação em 20/05/2011

\footnotetext{
${ }^{38}$ Da complexidade desses nexos na tradição francesa pode-se ter uma amostra pela discussão colocada por Gauchet, a propósito do debate sobre os direitos do homem na época da Revolução (GAUCHET, Marcel. La Révolution des droits de l'homme. Paris: Gallimard, 1989).
} 